ORIGINAL RESEARCH ARTICLE

\title{
Intimate Partner Violence Victimization and Associated Factors among Male and Female University Students in 22 Countries in Africa, Asia and the Americas
}

\author{
Supa Pengpid ${ }^{1,2}$ and Karl Peltzer ${ }^{1,2,3} *$
}

ASEAN Institute for Health Development, Madidol University, Salaya, Phutthamonthon, Nakhon Pathom, Thailand ${ }^{1}$; Department of Research and Innovation, University of Limpopo, Sovenga, South Africa ${ }^{2}$; HIV/AIDS/STI/and TB (HAST), Human Sciences Research Council, Pretoria, South Africa ${ }^{3}$.

*For Correspondence: Email: karl.pel@mahidol.ac.th :Phone: +66 24410207

\begin{abstract}
The study aimed at investigating the prevalence of intimate partner violence (IPV) and its associated factors among male and female university students in 22 countries in Africa, the Americas and Asia. In a cross-sectional questionnaire survey, data were collected from 16979 undergraduate university students, $49.3 \%$ male and $50.7 \%$ female, with an overall mean age of 21.8 years $(\mathrm{SD}=3.4)$. Of $7032(41.9 \%)$ students who had been sexually active in the past 12 months, $16.3 \%$ reported ever having experienced physical or sexual IPV, 15.4\% among men and $17.2 \%$ among women, physical IPV was $11.3 \%$ among men and $10.4 \%$ among women, and the proportion of ever having experienced sexual IPV was $9.3 \%$ among men and $11.3 \%$ among women. In multivariate logistic regression analyses, among both men and women, sociodemographic factors (senior study year, living in a low or lower middle income country) and risk factors (history of childhood physical and sexual abuse, made someone pregnant or had been pregnant, having had two or more sexual partners in the past 12 months, current tobacco use and having PTSD symptoms) were associated with physical and/or sexual violence victimization. High burden of IPV was found and several factors identified that may help guide intervention efforts. (Afr. J Reprod Health 2016; 20[1]: 29-39).
\end{abstract}

Keywords: partner violence, undergraduate students, sociodemographic factors, risk factors, protective factors, multi-country.

\section{Résumé}

L'étude visait à étudier la prévalence de la violence du partenaire intime (VPI) et ses facteurs associés chez les étudiants et étudiantes universitaires dans 22 pays en Afrique, aux Amériques et en Asie. Dans une enquête à travers des questionnaires transversale, les données ont été recueillies auprès des 16979 étudiants universitaires de premier cycle, dont 49,3\%étaient des 'hommes et 50,7\% étaient des femmes, avec un âge moyen global de 21,8 ans $(\mathrm{SD}=3,4)$. De $7032(41,9 \%)$ des étudiants qui avaient été sexuellement actifs au cours des 12 derniers mois, 16,3\% ont déclaré avoir déjà subi des violences physiques ou VPI (sexuelle). 15,4\% parmi les hommes et 17,2\% parmi les femmes, le taux de la VPI (physique) était de 11,3\% chez les hommes et $10,4 \%$ chez les femmes, et la proportion de ceux qui ont déjà subi la VPI (sexuelle) était de 9,3\% chez les hommes et de $11,3 \%$ chez les femmes. A travers les analyses de la régression logistique multivariée, tant chez les hommes que chez les femmes, les facteurs sociodémographiques (appartenant à un niveau élevé d'étude, habitant dans un pays à revenu faible ou à revenu moyen inférieur) et les facteurs de risque (histoire du mauvais traitement et des sévices sexuels subi par l'enfant, avait engrossé quelqu'un ou avait été enceinte, ayant eu deux ou plus des partenaires sexuels au cours des 12 derniers mois, la consommation courant du tabac et ayant des symptômes du SSPT) ont été associés à la violence physique et / ou sexuelle. Nous avons découvert un haut fardeau de VPI et avons identifié plusieurs facteurs qui peuvent guider les efforts d'intervention. (Afr. J Reprod Health 2016; 20[1]: 29-39).

Mots-clés: violence du partenaire, étudiants de premier cycle universitaire, facteurs sociodémographiques, facteurs de risque, facteurs de protection, multi-pays.

\section{Introduction}

Intimate Partner Violence (IPV) includes any behaviour that causes physical, psychological or sexual harm within an intimate relationship ${ }^{1}$, one can be a victim or perpetrator of IPV ${ }^{1}$.IPV is an important public health problem globally and in low- and middle- income countries ${ }^{1,2}$, and has negative health implications, which may include sexually transmitted infections, injury, unintended pregnancy, poor mental health, and addiction ${ }^{2-8}$. In a study utilizing the Demographic and Health Survey in 30 low- and middle-income countries, an overall prevalence of $29 \%$ of young ever- 
marrried/cohabitating adult women (20-24 years) reported lifetime physical or sexual IPV ${ }^{2}$. IPV is increasingly becoming a public health problem among young persons and male and female university students $^{9-11}$. Among university students in high income countries, e.g., in Finnland $42.0 \%$ reported physical violence ${ }^{12}$ in Poland $34.3 \%$ of females and $28.4 \%$ of males reported sexual aggression victimization ${ }^{13}$ and in Spain $15.2 \%$ of females reported lifetime genderbased violence victimization ${ }^{14}$. Among university students in low- and middle-income countries, e.g., in Chile $31 \%$ of women and $21 \%$ of men reported exposure to sexual violence ${ }^{15}$ in China the rates of being the victim of physical assault and sexual coercion were $18.0 \%$ and $5.1 \%$, respectively ${ }^{16}$ in Nigeria (females) $44.1 \%$ reported life-time prevalence of IPV $^{17} 46.7 \%$ sexual violence $^{18}$ and $22.8 \%$ and $22.2 \%$ of students experienced physical and sexual violence, respectively ${ }^{19}$ in Russia $25.5 \%$ were the victims of physical partner violence and $24.1 \%$ were sexually coerced in the previous year ${ }^{20}$ and in Uganda $10 \%$, with no significant gender differences, had exposure to physical partner violence ${ }^{9}$.

Individual-, family-, and contextual-level factors may contribute to IPV ${ }^{9,21}$. These may be conceptualized as sociodemographic, individual risk factors and protective factors ${ }^{21-23}$. Sociodemographic factors for IPV among university students may include, female gender (although some report similar proportions of IPV between females and males) ${ }^{16,20,24,25}$ earlier year of study $^{18}$ being single ${ }^{17,19}$ and residing in a campus residence ${ }^{19}$. Individual risk factors for IPV may include childhood physical or sexual abuse or other prior victimization as well as history of interparental violence $e^{17,18,25,26}$ substance use (alcohol and tobacco use) ${ }^{17,27-29}$ posttraumatic stress disorder (PTSD), depression, and suicidal behaviour $^{14,16,24,30,31}$ and sexual risk behaviour, including sexually transmitted infections (STI) and HIV $^{32-34}$. Protective factors may include lack of peer and parental social support ${ }^{22}$ lack of life satisfaction $^{20,24}$ high religiosity ${ }^{35}$ low perceived control $^{36}$ lower Gross national income but not family income ${ }^{37}$. There is a lack of information on IPV among male and female university students in Africa, the Americas and Asia. Therefore, this study aimed to investigate the prevalence of IPV (physical and sexual violence) and its relationship with sociodemographic, risk and protective factors among male and female university students in 22 countries in Africa, the Americas and Asia.

\section{Methods}

\section{Study setting, design and sample}

This cross-sectional study was part of a larger investigation of a range of health behaviours in university students, and was conducted with a network of researchers in participating countries (see Acknowledgments). The country selection was a convenient sample, with targeting a large spread of countries in Africa, Asia and the Americas. The questionnaire utilized for data collection was developed in English, then translated and backtranslated into languages (Arabic, Bahasa, Chinese, Filipino, French, Lao, Thai, Turkish) of the participating countries. In each study country, undergraduate students were surveyed in classrooms selected through a stratified random sample procedure (one university department randomly selected from each faculty as a primary sampling unit, and for each selected department randomly ordered undergraduate courses). Informed consent was obtained from participating students, and the study was conducted in 2013. Participation rates were in most countries more than $90 \%$. Ethics approvals were obtained from all participating institutions.

\section{Study Instrument}

Partner violence victimization was assessed with two items: 1) "Have you ever been hit by a sexual partner?", and 2) "Have you ever been forced to have sex?" Response options were 'yes' and 'No'. These items were adapted from the Conflict Tactics Scale ${ }^{38}$. Sociodemographic factors included age, gender, year of study, marital status, residential status and subjective socioeconomic family background ${ }^{39}$.

\section{Risk factors}

Childhood abuse was measured with two items: 1) "Have you ever been physically abused as a 
child?", and 2) "Have you ever been sexually abused as a child?" Response options were 'yes' and 'No' 40 .

\section{Sexual risk behaviour and reproductive health}

Items included 'How many sexual partners have you had in the past 12 months?' 'Condom use consistency with the primary partner in the past three months.' 'Alcohol use in the context of sex was assessed for in the past three months.' 'Have you ever been diagnosed with a sexually transmitted infection?' 'During the past 12 months, how often did you and your partner use any method of birth control?' Pregnancy history was assessed with the question, "Have you ever made someone pregnant/been pregnant? ${ }^{41,42}$.

Tobacco use was assessed with the question: Do you currently use one or more of the following tobacco products (cigarettes, snuff, chewing tobacco, cigars, etc.)? Response options were "yes" or "no" 43 .

Post traumatic stress disorder (PTSD). Breslau's 7-item screener was used to identify PTSD symptoms in the past month ${ }^{44}$. Participants who scored four or more were considered to have a positive screen for PTSD ${ }^{44}$. (Cronbach alpha= $0.75)$.

The Centres for Epidemiologic Studies Depression Scale (CES-D: 10 item) was used to assess depressive symptoms ${ }^{45}$. Scores 15 or more were classified as severe depressive symptoms ${ }^{45}$. $($ Cronbach alpha $=0.74)$.

\section{Protective factors}

Self-rated health status was assessed by a single item, "In general, would you say that your health is...Excellent, Very good, Good, Fair or Poor" ${ }^{\text {"46 }}$ Life satisfaction was elicited with one question, "All things considered, how satisfied are you with your life as a whole?" Response options ranged from $1=$ Very satisfied to $5=$ Very dissatisfied ${ }^{46}$. Intrinsic religiosity (or subjective religiosity) was assessed with three items of The Duke University Religion Index (DUREL) ${ }^{47}$ ( Cronbach alpha 0.81). Three items measured personal control (e.g., "I can do just about anything I really set my mind to" $)^{48}$ (Cronbach's alpha 0.75). Social support was measured with three items from the Social Support Questionnaire $^{49}$. (Cronbach's alpha 0.95). Country income was assessed using World Bank classifications $^{50}$.

\section{Data analysis}

The data were analysed using IBM SPSS (version 22.0). Stratified analysis was done for male and female university students. The proportion of sociodemographic factors, risk factors and protective factors was calculated as a percentage. Logistic regression analyses were conducted with STATA to calculate the crude odds ratio (OR) with 95\% confidence interval (CI) to determine the associations between the potential determinants and IPV. All variables that were statistically significant $(\mathrm{P}<.05)$ in bivariate analyses were included in the multivariable model. Predictor variables were entered in a single step. The country was entered as the primary sampling unit for survey analysis in STATA so as to get accurate CIs, given the clustered nature of the data.

\section{Results}

\section{Sample characteristics}

Of the total sample of 16979 undergraduate university students from 23 universities in 22 countries, 7032 (41.9\%) reported to have been sexually active in the past 12 months, $49.3 \%$ male and $50.7 \%$ female, with an overall mean age of 21.8 years $(\mathrm{SD}=3.4)$. Of those who had been sexually active in the past 12 months, $16.3 \%$ reported ever having experienced IPV (physical or sexual partner violence), $15.4 \%$ among men and $17.2 \%$ among women. The proportion of ever having experienced physical partner violence was $11.3 \%$ among men and $10.4 \%$ among women, and the proportion of ever having experienced sexual partner violence was $9.3 \%$ among men and $11.3 \%$ among women. A large variation in IPV prevalence among sexually active students by country was found, from $7.4 \%$ in Mauritius to $47.9 \%$ in Cameroon in the African region, from $6.2 \%$ in 
Table 1: Sample Characteristics and Intimate Partner Violence by Country and by sex, 2013

\begin{tabular}{|c|c|c|c|c|c|c|c|c|c|c|}
\hline & \multirow{2}{*}{$\begin{array}{l}\text { Total } \\
\text { sample } \\
\text { N }\end{array}$} & \multicolumn{2}{|c|}{ Sexually active sample } & \multicolumn{2}{|c|}{$\begin{array}{l}\text { Intimate } \\
\text { violence }\end{array}$} & \multirow{2}{*}{$\begin{array}{l}\text { partner } \\
\text { Female }\end{array}$} & \multicolumn{2}{|l|}{$\begin{array}{l}\text { Physical } \\
\text { violence }\end{array}$} & \multicolumn{2}{|c|}{ Sexual violence } \\
\hline & & $\mathbf{N}(\%)$ & $\begin{array}{l}\text { Age } \\
\text { M (SD) }\end{array}$ & All & Male & & Male & $\begin{array}{l}\text { Femal } \\
\text { e }\end{array}$ & Male & Female \\
\hline All & 16979 & $7032(41.9)$ & $21.8(3.5)$ & 16.3 & 15.4 & 17.2 & 11.3 & 10.4 & 9.3 & 11.3 \\
\hline \multicolumn{11}{|l|}{ Africa } \\
\hline Cameroon & 627 & $286(45.6)$ & $21.6(2.6)$ & 47.9 & 45.9 & 51.5 & 43.2 & 48.5 & 22.7 & 18.8 \\
\hline Ivory Coast & 824 & $604(73.3)$ & $24.0(2.6)$ & 20.3 & 11.4 & $30.2 *$ & 3.8 & $12.7 *$ & 8.9 & $26.8 *$ \\
\hline Madagascar & 800 & $323(40.4)$ & $20.4(1.8)$ & 15.2 & 14.7 & 15.9 & 11.5 & 6.3 & 5.3 & 11.1 \\
\hline Mauritius & 501 & $148(29.5)$ & $21.0(1.2)$ & 7.4 & 8.3 & 6.7 & 6.7 & 4.0 & 5.0 & 5.3 \\
\hline Namibia & 503 & $344(68.4)$ & $22.0(3.7)$ & 19.2 & 17.7 & 21.5 & 6.2 & 7.4 & 15.0 & 15.0 \\
\hline Nigeria & 820 & $328(40.0)$ & $21.7(2.7)$ & 17.6 & 19.2 & 15.1 & 11.9 & 6.6 & 11.7 & 14.8 \\
\hline South Africa & 888 & 635 (74.9) & $22.6(3.7)$ & 18.3 & 18.1 & 18.5 & 11.1 & 14.3 & 12.5 & 9.8 \\
\hline Tunisia & 960 & $164(17.1)$ & $21.6(2.2)$ & 7.5 & 8.7 & 6.4 & 2.9 & 1.3 & 7.2 & 7.5 \\
\hline \multicolumn{11}{|c|}{ Caribbean and Latinamerica } \\
\hline Barbados & 580 & $421(72.6)$ & $22.0(2.8)$ & 13.9 & 9.8 & $19.6^{*}$ & 7.2 & 12.4 & 5.1 & $14.9 * *$ \\
\hline Grenada & 435 & $307(70.6)$ & $24.8(6.0)$ & 22.6 & 20.0 & 23.5 & 16.8 & 15.5 & 9.5 & 16.1 \\
\hline Jamaica & 762 & $524(68.8)$ & $21.6(5.5)$ & 21.3 & 16.0 & 23.0 & 8.4 & 8.6 & 12.2 & 18.8 \\
\hline Colombia & 816 & $699(85.7)$ & $21.3(3.3)$ & 6.9 & 4.0 & $9.4^{*}$ & 3.4 & 7.5 & 1.2 & 2.7 \\
\hline Venezuela & 564 & $425(75.5)$ & $20.9(2.9)$ & 6.2 & 5.9 & 6.5 & 3.0 & 4.1 & 3.5 & 4.6 \\
\hline \multicolumn{11}{|l|}{ Asia } \\
\hline China & 1184 & $143(2.1)$ & $21.0(2.6)$ & 4.2 & 6.5 & 3.1 & 4.3 & 2.1 & 2.2 & 2.1 \\
\hline India & 800 & $116(14.5)$ & $18.0(0.9)$ & 12.1 & 16.0 & 2.9 & 13.6 & 2.9 & 8.6 & 2.9 \\
\hline Indonesia & 750 & $186(24.8)$ & $20.0(4.2)$ & 1.6 & 1.6 & 1.6 & 1.6 & 0.8 & 0.0 & 0.8 \\
\hline Kyrgyzstan & 837 & $372(44.4)$ & $21.6(1.7)$ & 45.4 & 42.2 & 54.7 & 37.9 & $54.7 *$ & 23.5 & 15.8 \\
\hline Laos & 806 & $280(34.7)$ & $22.6(1.7)$ & 1.8 & 0.0 & 3.4 & 0.0 & 0.7 & 0.0 & 3.4 \\
\hline Philippines & 968 & $67(8.9)$ & $19.3(1.3)$ & 17.9 & 21.4 & 15.4 & 3.6 & 5.1 & 17.9 & 15.4 \\
\hline Singapore & 894 & 166 (18.6) & $21.7(1.7)$ & 6.7 & 6.4 & 7.5 & 5.5 & 3.8 & 5.5 & 7.5 \\
\hline Thailand & 860 & 281 (34.6) & $20.6(1.2)$ & 9.9 & 13.9 & 6.6 & 7.4 & 3.3 & $12.3 *$ & 3.3 \\
\hline Turkey & 800 & $212(26.5)$ & $21.6(2.7)$ & 5.7 & 4.4 & 9.6 & 3.1 & 7.7 & 3.1 & 3.8 \\
\hline
\end{tabular}

$* * \mathrm{P}<0.001$ or $* \mathrm{P}<0.01$

Venezuela to $22.6 \%$ in Grenada in the Americas region, and $1.6 \%$ in Indonesia to $45.4 \%$ in Kyrgyzstan in the Asian region (See Table 1).

\section{Independent variables description among sexually active participants}

Regarding study year, $29.5 \%$ were in the first study year, $23.2 \%$ in the second, $25.1 \%$ third and $22.2 \%$ in the fourth study year, $6.9 \%$ were married, $54.5 \%$ lived away from their parents or guardians on their own or on campus, $46.2 \%$ were well-off or wealthy by economic family background, and $63 . \%$ were living in an upper middle or high income country. In terms of risk factors, $7.3 \%$ had been physically abused as a child, $4.6 \%$ had been sexually abused as a child, and $18.3 \%$ were current tobacco users. Almost a third of the sample $(31.2 \%)$ had two or more sexual partners in the past 12 months, $24.1 \%$ drank alcohol in the context of sex in the past 3 months, $7.8 \%$ reported ever being diagnosed with a sexually transmitted infection (STI), and 17.8\% had been pregnant or had made someone pregnant. Most (66.4\%) had inconsistently (not always) used a condom with the primary partner in the past three months and $72.3 \%$ had inconsistently (not always) used contraceptives in the past 12 months. In terms of mental health, $13.2 \%$ screened positive for severe depression and $21.1 \%$ for PTSD. Regarding protective factors, $64.9 \%$ had medium or high intrinsic religiosity, $33.7 \%$ high personal control, $45.8 \%$ high social support, and the mean self-rated health status was 3.07 (range 1-5) and the mean life satisfaction 2.79 (range 1-5) (see Table 2).

\section{Associations with IPV prevalence among men and women}

Multivariate logistic regression among male university students found that sociodemographic factors (in the second and fourth year of study, residing away from parents or guardians on their own or on campus, coming from a wealthier family background, and living in a low or lower middle 
Table 2: Sample Characteristics by Independent Variables and Intimate Partner Violence

\begin{tabular}{|c|c|c|c|}
\hline \multirow[t]{3}{*}{ Variables } & \multirow{3}{*}{$\begin{array}{l}\text { All } \\
\mathrm{N}(\%)\end{array}$} & \multicolumn{2}{|c|}{ Intimate partner violence } \\
\hline & & Men & Women \\
\hline & & $\mathbf{N}(\%)$ & $\mathbf{N}(\%)$ \\
\hline \multicolumn{4}{|l|}{ Sociodemographics } \\
\hline \multicolumn{4}{|l|}{ Year of study } \\
\hline First & $2061(29.5)$ & $101(10.9)$ & $189(17.8)$ \\
\hline Second & $1619(23.2)$ & $120(15.6)$ & $126(15.7)$ \\
\hline Third & $1751(25.1)$ & $120(15.0)$ & $11.7(13.2)$ \\
\hline Fourth & $1548(22.2)$ & $183(21.7)$ & $154(22.6)$ \\
\hline Married (vs. single) & $483(6.9)$ & $30(20.4)$ & $86(26.6)$ \\
\hline \multicolumn{4}{|l|}{ Residence } \\
\hline Live with parents/guardian & $3182(45.5)$ & $188(12.7)$ & $289(18.0)$ \\
\hline Away from parents/guardian & $3813(54.5)$ & $337(17.9)$ & $301(16.4)$ \\
\hline \multicolumn{4}{|l|}{ Family wealth } \\
\hline Not well off/Poor & $3728(53.8)$ & $193(11.2)$ & $311(16.6)$ \\
\hline Wealthy/Quite well off & $3205(46.2)$ & $327(20.3)$ & $277(18.1)$ \\
\hline \multicolumn{4}{|l|}{ Country income } \\
\hline Upper middle/high & $4492(63.5)$ & $204(10.6)$ & $360(14.9)$ \\
\hline Low income/lower middle & $2577(36.5)$ & $322(22.2)$ & $235(22.4)$ \\
\hline \multicolumn{4}{|l|}{ Risk factors } \\
\hline History of child physical abuse & $509(7.3)$ & $90(37.2)$ & $112(47.5)$ \\
\hline History of child sexual abuse & $318(4.6)$ & $52(51.5)$ & $92(47.2)$ \\
\hline Ever (made someone) pregnant & $1216(17.8)$ & $132(26.5)$ & $226(34.1)$ \\
\hline Two or more sexual partners in the past 12 months & $2049(31.2)$ & $299(21.7)$ & $198(32.5)$ \\
\hline History of STI & $539(7.8)$ & $55(22.4)$ & $61(21.9)$ \\
\hline Alcohol use in the context of sex in the past 3 months & $1496(24.1)$ & $195(21.7)$ & $147(25.8)$ \\
\hline Current tobacco users & $1168(18.3)$ & $205(23.6)$ & $79(28.9)$ \\
\hline Inconsistent condom use & $4079(66.4)$ & $311(16.5)$ & $393(18.8)$ \\
\hline Inconsistent contraceptive use & $4436(72.3)$ & $341(16.1)$ & $412(19.0)$ \\
\hline Depression symptoms & $930(13.2)$ & $89(23.3)$ & $157(30.6)$ \\
\hline PTSD symptoms & $1404(21.1)$ & $147(25.1)$ & $225(28.9)$ \\
\hline \multicolumn{4}{|l|}{ Protective factors } \\
\hline \multicolumn{4}{|l|}{ Intrinsic religiosity } \\
\hline Low & $2481(35.1)$ & $183(13.7)$ & $146(13.3)$ \\
\hline Medium & $2630(37.2)$ & $178(14.8)$ & $248(18.7)$ \\
\hline High & $1985(27.7)$ & $165(19.6)$ & $201(19.5)$ \\
\hline \multicolumn{4}{|l|}{ Personal control } \\
\hline Low & $1874(26.5)$ & $155(17.1)$ & $165(18.5)$ \\
\hline Medium & $2810(39.8)$ & $229(17.0)$ & $252(18.3)$ \\
\hline High & $2385(33.7)$ & $142(12.7)$ & $178(14.9)$ \\
\hline \multicolumn{4}{|l|}{ Social support } \\
\hline High & $3154(45.8)$ & $168(11.7)$ & $253(15.5)$ \\
\hline \multirow[t]{2}{*}{ Low } & $3736(54.2)$ & $347(18.7)$ & $334(19.0)$ \\
\hline & $\mathrm{M}(\mathrm{SD})$ & $\mathrm{M}(\mathrm{SD})$ & $\mathrm{M}(\mathrm{SD})$ \\
\hline Self-perceived health (range 1-5) & $3.07(1.1)$ & $3.19(1.2)$ & $2.92(1.0)$ \\
\hline Life satisfaction (range 1-5) & $2.79(1.3)$ & $2.53(1.3)$ & $2.81(1.2)$ \\
\hline
\end{tabular}

income country), risk factors (history of childhood physical and sexual abuse, made someone pregnant, having had two or more sexual partners in the past 12 months, current tobacco use and having PTSD symptoms), and lack of protective factors (poor life satisfaction and low social support) were associated with physical and/or sexual violence victimization (See Table 3). Multivariate logistic regression among female university students found that sociodemographic factors (in the fourth year of study and living in a low- or lower middle- income country), risk factors (history of childhood physical and sexual abuse, having been pregnant, having had two or more sexual partners in the past 12 months, alcohol use in the context of sex, current tobacco use, having depressive and PTSD symptoms), and lack of protective factors (poor subjective health status) were associated with physical and/or sexual violence victimization (See Table 4). 
Table 3: Associations with Intimate Partner Violence among Men

\begin{tabular}{|c|c|c|}
\hline Variables & UOR $(95 \%$ CI) & AOR (95\% CI) \\
\hline \multicolumn{3}{|l|}{ Sociodemographics } \\
\hline \multicolumn{3}{|l|}{ Year of study } \\
\hline First & 1.00 & 1.00 \\
\hline Second & $1.60(1.20-2.14)^{* *}$ & $1.80(1.232 .64)^{* *}$ \\
\hline Third & $1.52(1.14-2.02)^{* *}$ & $1.36(0.93-2.00)$ \\
\hline Fourth & $2.37(1.82-3.10)^{* * *}$ & $1.80(1.25-2.60)^{* *}$ \\
\hline Married (vs. single) & $1.40(0.91-2.14)$ & --- \\
\hline \multicolumn{3}{|l|}{ Residence } \\
\hline Live with parents/guardian & 1.00 & 1.00 \\
\hline Away from parents/guardian & $1.50(1.23-1.82)^{* * *}$ & $1.41(1.10-1.81)^{* *}$ \\
\hline \multicolumn{3}{|l|}{ Family wealth } \\
\hline Not well off/Poor & 1.00 & 1.00 \\
\hline Wealthy/Quite well off & $2.05(1.68-2.48)^{* * *}$ & $2.22(1.70-2.89)^{* * *}$ \\
\hline \multicolumn{3}{|l|}{ Country income } \\
\hline Upper middle/high & 1.00 & 1.00 \\
\hline Low income/lower middle & $2.49(2.05-3.02)^{* * *}$ & $2.61(1.97-3.45) * * *$ \\
\hline \multicolumn{3}{|l|}{ Risk factors } \\
\hline History of child physical abuse & $3.58(2.70-4.75)^{* * *}$ & $2.37(1.56-3.62) * * *$ \\
\hline History of child sexual abuse & $6.15(4.08-9.26)^{* * *}$ & $3.87(2.12-7.06) * * *$ \\
\hline Ever (made someone) pregnant & $2.22(1.76-2.78)^{* * *}$ & $1.87(1.38-2.53) * * *$ \\
\hline Two or more sexual partners in the past 12 months (base $=1$ ) & $2.15(1.77-2.61)^{* * *}$ & $1.78(1.39-2.29)^{* * *}$ \\
\hline History of STI & $1.59(1.15-2.19)^{* *}$ & $0.98(0.64-1.48)$ \\
\hline Alcohol use in the context of sex in the past 3 months & $1.63(1.33-1.90)^{* * *}$ & $1.27(0.97-1.66)$ \\
\hline Tobacco users & $2.09(1.71-2.56)^{* * *}$ & $1.301 .01-1.68)^{*}$ \\
\hline Inconsistent condom use & $0.97(0.80-1.19)$ & --- \\
\hline Inconsistent contraceptive use & $0.99(0.79-1.24)$ & --- \\
\hline Depression symptoms & $1.77(1.37-2.30)^{* * *}$ & $1.36(0.96-1.94)$ \\
\hline PTSD symptoms & $2.18(1.75-2.71)^{* * *}$ & $1.63(1.21-2.20) * * *$ \\
\hline \multicolumn{3}{|l|}{ Protective factors } \\
\hline Self-perceived health & $1.07(0.99-1.16)$ & --- \\
\hline Life satisfaction & $0.84(0.78-0.90)^{* * *}$ & $0.90(0.80-0.99)^{*}$ \\
\hline \multicolumn{3}{|l|}{ Intrinsic religiosity } \\
\hline Low & 1.00 & 1.00 \\
\hline Medium & $1.11(0.89-1.39)$ & $0.81(0.61-1.09)$ \\
\hline High & $1.54(1.22-1.94)^{* * *}$ & $1.27(0.94-1.73)$ \\
\hline \multicolumn{3}{|l|}{ Personal control } \\
\hline Low & 1.00 & 1.00 \\
\hline Medium & $0.98(0.79-1.23)$ & $1.06\left(\begin{array}{lll}0.79 & 1.42)\end{array}\right.$ \\
\hline High & $0.70(0.55-0.90)^{* *}$ & $0.78(0.57-1.08)$ \\
\hline \multicolumn{3}{|l|}{ Social support } \\
\hline High & 1.00 & 1.00 \\
\hline Low & $1.75(1.43-2.13)^{* * *}$ & $1.64(1.27-2.12) * * *$ \\
\hline
\end{tabular}

*** $\mathrm{p}<0.001, * * \mathrm{p}<0.01, * \mathrm{p}<0.05$, UOR, Unadjusted Odds Ratio; AOR, Adjusted Odds Ratio; CI, Confidence Interval.

Table 4: Associations with Intimate Partner Violence among Women

\begin{tabular}{lll}
\hline Variables & UOR $(95 \%$ CI $)$ & AOR $(95 \%$ CI $)$ \\
\hline Sociodemographics & & \\
Year of study & 1.00 & 1.00 \\
$\quad$ First & $0.86(0.67-1.10)$ & $0.93(0.66-1.31)$ \\
$\quad$ Second & $0.70(0.54-0.89)^{* *}$ & $0.73(0.52-1.04)$ \\
$\quad$ Third & $1.35(1.06-1.72)^{*}$ & $1.59(1.13-2.24)^{* *}$ \\
$\quad$ Fourth & $1.88(1.44-2.45)^{* * *}$ & $1.31(0.90-1.90)$ \\
Married (vs. single) & & \\
Residence & 1.00 & --- \\
$\quad$ Live with parents/guardian & & \\
\hline
\end{tabular}




\begin{tabular}{|c|c|c|}
\hline Away from parents/guardian & $0.90(0.75-1.07)$ & \\
\hline \multicolumn{3}{|l|}{ Family wealth } \\
\hline Not well off/Poor & 1.00 & --- \\
\hline Wealthy/Quite well off & $1.12(0.94-1.34)$ & \\
\hline \multicolumn{3}{|l|}{ Country income } \\
\hline Upper middle/high & 1.00 & 1.00 \\
\hline Low income/lower middle & $1.65(1.38-1.98) * * *$ & $1.88(1.42-2.50) * * *$ \\
\hline \multicolumn{3}{|l|}{ Risk factors } \\
\hline History of child physical abuse & $5.19(3.95-6.82) * * *$ & $3.32(2.16-5.10) * * *$ \\
\hline History of child sexual abuse & $4.91(3.64-6.61)^{* * *}$ & $2.17(1.36-3.47)^{* * * *}$ \\
\hline Ever (made someone) pregnant & $3.44(2.82-4.19) * * *$ & $2.73(1.07-3.61) * * *$ \\
\hline Two or more sexual partners in the past 12 months (base $=1$ ) & $2.92(2.38-3.57) * * *$ & $2.44(1.85-3.22)^{* * *}$ \\
\hline History of STI & $1.39(1.03-1.88)^{*}$ & $0.73(0.48-1.11)$ \\
\hline Alcohol use in the context of sex in the past 3 months & $1.72(1.38-2.13)^{* * *}$ & $1.40(1.05-1.87)^{*}$ \\
\hline Tobacco users & $2.18(1.64-2.89)^{* * *}$ & $1.83(1.26-2.65)^{* * *}$ \\
\hline Inconsistent condom use & $1.11(0.90-1.36)$ & --- \\
\hline Inconsistent contraceptive use & $1.38(1.11-1.71)^{* *}$ & $1.20(0.91-1.59)$ \\
\hline Depression symptoms & $2.52(2.04-2.12)^{* * *}$ & $1.89(1.38-2.59) * * *$ \\
\hline PTSD symptoms & $2.65(2.18-3.21)^{* * *}$ & $1.92(1.44-2.55)^{* * *}$ \\
\hline \multicolumn{3}{|l|}{ Protective factors } \\
\hline Self-perceived health & $0.89(0.82-0.97) * *$ & $0.86(0.76-0.98)^{*}$ \\
\hline Life satisfaction & $0.99(0.82-0.97)$ & --- \\
\hline \multicolumn{3}{|l|}{ Intrinsic religiosity } \\
\hline Low & 1.00 & 1.00 \\
\hline Medium & $1.50(1.20-1.89) * * *$ & $1.24(0.91-1.67)$ \\
\hline High & $1.59(1.26-2.01)^{* * *}$ & $1.35(0.98-1.87)$ \\
\hline \multicolumn{3}{|l|}{ Personal control } \\
\hline Low & 1.00 & 1.00 \\
\hline Medium & $0.99(0.80-1.23)$ & $1.10(0.81-1.52)$ \\
\hline High & $0.76(0.61-0.96)^{*}$ & $0.91(0.65-1.26)$ \\
\hline \multicolumn{3}{|l|}{ Social support } \\
\hline High & 1.00 & 1.00 \\
\hline Low & $1.27(1.06-1.52)^{* *}$ & $1.16(0.90-1.49)$ \\
\hline
\end{tabular}

*** $\mathrm{p}<0.001, * * \mathrm{p}<0.01, * \mathrm{p}<0.05$, UOR, Unadjusted Odds Ratio; AOR, Adjusted Odds Ratio; CI, Confidence Interval.

\section{Discussion}

The results of this large study among university students in 22 countries found that by the age of 21 years, $16.3 \%$ of sexually active (15.4\% among men and $17.2 \%$ among women) reported ever having experienced IPV (physical or sexual partner violence). These prevalences seem to compare with several previous studies among university students, e.g. in China ${ }^{16}$ and Uganda ${ }^{9}$ and were somewhat lower to what was found in Chile ${ }^{15}$, Nigeria ${ }^{16-18}$, Russia $^{20}$ and in the International Dating Violence (IDV) Study in 21 mainly high income countries ${ }^{24}$. A large variation of IPV prevalence among sexually active students by country was found, ranging from $7.4 \% \quad(6.7 \%$ for females $)$ in Mauritius to $47.9 \%$ (51.5\% for females) in Cameroon in the African region, from $6.2 \%(6.5 \%$ for females) in Venezuela to $22.6 \%(23.5 \%$ in females) Grenada in the Americas region, and ranging from $1.6 \%$ (1.6\% in females) in Indonesia to $45.4 \%$ (54.7\% in females) in Kyrgyzstan in the Asian region. Compared to the previous IDV study $^{24}$, this study also found lower rates of physical and sexual partner violence in China (27.2\% physical violence and $15.4 \%$ sexual violence victimization, compared to $4.3 \%$ and $2.2 \%$, respectively, in this survey), India (35.5\% physical violence and $18.6 \%$ sexual violence victimization, compared to $2.9 \%$ and $2.9 \%$, respectively, in this survey) and Singapore (18.4\% physical violence and $23.7 \%$ sexual violence victimization, compared to $3.8 \%$ and $7.5 \%$, respectively, in this survey ${ }^{24}$. It is possible that the use of the Conflict Tactics Scale with a number of items assessing various forms of violence in the IDV study compared to having only two broad violence questions in this study contributed to 
higher prevalences of IPV in the IDV study. A lower variation and a higher prevalence of physical or sexual partner violence $(29.5 \%$, compared with $17.2 \%$ in this survey) was found among population-based national samples in evermarried/cohabitating young adult women (slightly older, aged 20-24 years) in 30 low- and middleincome countries ${ }^{2}$. Regarding the country variation, compared to the population-based study ${ }^{2}$, this study found similar prevalences of IPV among women in Cameroon (43.7\% in the DHS and $51.5 \%$ in this survey), Nigeria (16.5\% and $15.1 \%)$ and the Philippines $(15.9 \%$ and $15.4 \%$, respectively), while higher rates in the DHS compared with this study were found in Columbia $(30.5 \%$ and $9.4 \%)$, and India $(34.8 \% \text { and } 2.9 \%)^{2}$. Some of the country differences in IPV may be attributed to cultural norms, substance use, and other forms of violence ${ }^{2,19}$. Health care providers should be aware about the high prevalence of physical and sexual partner violence and its health consequences in university students, especially in study countries (Cameroon and Kyrgyzstan) that are disproportionately affected by IPV, providing both prevention and survivor support ${ }^{2}$.

Regarding gender differences, generally, the proportion of ever having experienced physical partner violence was higher in men than in women, and the proportion of ever having experienced sexual partner violence was higher among female than male students, however, this was not significant. In most study countries, there were no significant gender differences in terms of physical and sexual IPV. In three countries (Barbados, Columbia, and Ivory Coast) IPV was significantly higher in female than male university students. Moreover, in university students from Kyrgyzstan physical partner violence victimization was significantly higher in women than men, and in Thailand sexual partner violence victimization was significantly higher in male than in female students. These findings are in concordance with previous studies indicating similar proportions of IPV between females and males, and a preponderance of female gender IPV victimization, especially sexual violence victimization ${ }^{16,20,24,25}$. This study found that being in a higher study year at university was associated with a higher prevalence of IPV, which may be explained by the possibility that at older ages more sexual partnerships are engaged into than at younger ages or earlier study years. In agreement with another study $^{19}$, this study found, among men, that living away from parents or guardians on campus or off campus on their own was associated with IPV. It is possible that more freedom of living on their own may be related to increased IPV. Unlike some previous studies ${ }^{17,19}$, this study found, among women that being married was associated with IPV in bivariate analysis, and among men that having greater family wealth was associated with IPV.

In terms of risk factors, this study found in multivariate logistic regression analyses, in agreement with a number of studies ${ }^{14,16-18,24-31}$, that having experienced childhood physical and sexual abuse, tobacco use, alcohol use in the context of sex, PTSD symptoms and depression symptoms were associated with IPV. In addition, sexual risk behaviour (having had two or more sexual partners in the past year) and having a history of an STI in bivariate analysis was found to be associated with IPV. Similar results were found in previous studies $^{32-34}$. Alcohol use in the context of sexual activity may reduce the ability to avoid violence ${ }^{17}$, 51 . Some studies found that although male and female university students may be exposed to similar rates of IPV, but IPV impacted more negatively on females than males in relation to mental health ${ }^{52}$. In this study poor mental health in terms of PTSD symptoms were in both men and women associated with IPV, while poor mental health in terms of depression symptoms was only among women and not men associated with IPV. Moreover, the study found that male students having made someone pregnant and female students having been pregnant were associated with higher IPV victimization. The increased vulnerability of pregnant women to IPV has been reported $^{53}$. There is also the possibility of increased unwanted pregnancy in the context of $\mathrm{IPV}^{54}$, but this was not assessed in this study.

In relation to protective factors, men that have low life satisfaction and low social support and women with low perceived health status were associated with IPV. Similar results were found in previous studies ${ }^{20,24}$. Low personal control and high religiosity was, in agreement with some other studies $^{35,36}$, associated with IPV. When designing 
strategies to prevent IPV protective factors such as improving life satisfaction, overall subjective health, social support and increasing perceived control may be important to incorporate. In agreement with a previous multicountry study ${ }^{37}$ lower Gross national income, but not family income among women was associated with IPV.

\section{Study limitations}

This study was only conducted in one or two universities in each country, the results are therefore not necessarily generalisable to other parts of each country. Furthermore, only participants who were studying at a university were included, which means that those who were not in a university were excluded. The cross-sectional design of the study does not allow for any causal conclusions regarding the direction of independent variables and IPV. Moreover, the assessment of exposure to violence was limited to two questions, while more details about the nature and context of IPV $^{55}$ should be assessed in future studies. A further limitation of the data was the low sexually active rates in some study countries $(<15 \%$ in China, India, and Philippines), limiting the sample sizes and estimates.

\section{Conclusion}

The findings show a significant burden of partner physical and sexual violence among undergraduate university students across 22 low- and middleincome countries. The current study identified sociodemographic variables, risk factors and protective factors that can help guide IPV prevention, intervention and support programmes for university students in this important developmental period.

\section{Declaration}

The authors declare that they have no competing interests.

\section{Contribution of authors}

SP and KP formulated the research design, analysed the data and wrote and approved the manuscript.

\section{References}

1. WHO. Global and regional estimates of violence against women: Prevalence and health effects of intimate partner violence and non-partner sexual violence. Geneva: World Health Organization; 2013.

2. Decker MR, Latimore AD, Yasutake S, Haviland M, Ahmed S, Blum RW, Sonenstein F, Astone NM. Gender-based violence against adolescent and young adult women in low- and middle-income countries. J Adolesc Health 2015; 56(2): 188-96.

3. Ellsberg M, Jansen HA, Heise L, Watts CH, GarciaMoreno C; WHO Multi-country Study on Women's Health and Domestic Violence against Women Study Team. Intimate partner violence and women's physical and mental health in the WHO multicountry study on women's health and domestic violence: An observational study. Lancet 2008; 371: $1165 \mathrm{e} 72$.

4. Decker MR, Silverman JG, Raj A. Dating violence and sexually transmitted disease/HIV testing and diagnosis among adolescent females. Pediatrics 2005; 116: e272e6.

5. Campbell JC. Health consequences of intimate partner violence. Lancet 2002; 359: 1331e6.

6. Nangolo LHN, Peltzer K. Violence against women and its mental health consequences in Namibia. Gender Behav 2003; 1: 16-33.

7. Peltzer K, Pengpid S. Sexual abuse, violence and HIV risk among adolescents in South Africa. Gender Behav 2008; 6(1): 1462-1478.

8. Peltzer K, Pengpid S, McFarlane J, Banyini M. Mental health consequences of intimate partner violence in Vhembe district, South Africa. Gen Hosp Psychiatry 2013; 35(5): 545-550.

9. Agardh A, Tumwine G, Asamoah BO, Cantor-Graae E. The invisible suffering: sexual coercion, interpersonal violence, and mental health--a crosssectional study among university students in southwestern Uganda. PLoS One 2012; 7(12): e51424.

10. Hines DA. Predictors of sexual coercion against women and men: a multilevel, multinational study of university students. Arch Sex Behav 2007; 36(3): 403-22.

11. Straus MA. Prevalence of violence against dating partners by male and female university students worldwide. Violence Against Women 2004; 10(7): 790-811.

12. Björklund K, Häkkänen-Nyholm H, Huttunen T, Kunttu K.Violence victimization among Finnish university students:revalence,symptoms and healthcare usage. Soc Sci Med 2010; 70(9): 1416-22.

13. Tomaszewska P, Krahé B. Sexual aggression victimization and perpetration among female and male university students in Poland. J Interpers Violence 2015; Oct 14. pii: 0886260515609583.

14. Vázquez FL, Torres A, Otero P. Genderbased violence and mental disorders in female college students. Soc Psychiatry Psychiatr 
Epidemiol 2012; 47(10): 1657-67.

15. Lehrer JA, Lehrer EL, Oyarzún PB. Sexual violence in young men and women in Chile: results from a 2005 survey of university students. Rev Med Chil 2009; 137(5): 599-608.

16. Su PY, Hao JH, Huang ZH, Xiao LM, Tao FB. An investigation on the epidemic situation of intimate partner violence in 2,575 college students. Zhonghua Liu Xing Bing Xue Za Zhi 2011; 32(4): 346-51.

17. Umana JE, Fawole OI, Adeoye IA. Prevalence and correlates of intimate partner violence towards female students of the University of Ibadan, Nigeria. BMC Womens Health 2014; 14: 131.

18. Mezie-Okoye MM, Alamina FF. Sexual violence among female undergraduates in a tertiary institution in Port Harcourt: prevalence, pattern, determinants and health consequences. Afr J Reprod Health 2014; 18(4): 79-85.

19. Iliyasu Z, Abubakar IS, Aliyu MH, Galadanci HS, Salihu HM. Prevalence and correlates of genderbased violence among female university students in Northern Nigeria. Afr J Reprod Health 2011; 15(3): 111-9.

20. Lysova AV, Douglas EM. Intimate partner violence among male and female Russian university students. J Interpers Violence 2008; 23(11): 1579-99.

21. Heise LL. Violence against women: An integrated, ecological framework. Violence Against Women 1998; 4: 262e90.

22. Ohene SA, Johnson K, Atunah-Jay, Owusu A. Sexual and physical violence victimization among senior high school students in Ghana: Risk and protective factors. Soc Sci Med 2015: doi:10.1016/j. socscimed.2015.10.019

23. Kaukinen C. Dating violence among college students: the risk and protective factors. Trauma Violence Abuse 2014; 15(4): 283-96.

24. Chan KL, Straus MA, Brownridge DA, Tiwari A, Leung WC. Prevalence of dating partner violence and suicidal ideation among male and female university students worldwide. J Midwifery Womens Health 2008;53(6): 529-37.

25. Gover AR, Park M, Tomsich EA, Jennings WG. Dating violence perpetration and victimization among South Korean collegestudents:a focuson gender and childhood maltreatment. $\mathrm{J}$ Interpers Violence 2011; 26(6): 1232-63.

26. Lehrer JA, Lehrer EL, Koss MP. Unwanted sexual experiences in young men: evidence from a survey ofuniversity students in Chile. Arch Sex Behav 2013; 42(2): 213-23.

27. Lysova $\mathrm{AV}$, Hines DA. Binge drinking and violence against intimate partners in Russia Aggress Behav 2008; 34(4): 416-27.

28. Crane CA, Hawes SW, Weinberger AH. Intimate partner violence victimization and cigarette smoking: a meta-analyticreview. Trauma Violence Abuse 2013; 14(4): 305-15.

29. Shorey RC, Stuart GL, Cornelius TL.
Dating violence and substance use in college students: A review of the literature. Aggress Violent Behav 2011; 16(6): 541-550.

30. Hines DA. Posttraumatic stress symptoms among men who sustain partner violence: An international multisite study of university students. Psychol Men Masculinity 2007; 8(4): 225-239.

31. Gelaye B, Arnold D, Williams MA, Goshu M, Berhane Y. Depressive symptoms among female college students experiencing gender-

based violence in Awassa, Ethiopia. J Interpers Violence 2009; 24(3): 464-81.

32. Gaffoor Z, Wand H, Daniels B, Ramjee G.

High risk sexual behaviors are associated with sexual violence among a cohort of women in Durban, South Africa. BMC Res Notes 2013; 6: 532.

33. Pitpitan EV, Kalichman SC, Eaton LA, Sikkema

KJ, Watt MH, Skinner D Gender-based violence and HIV sexual risk behavior: alcohol use and mental health problems as mediators among women in drinking venues, Cape Town. Soc Sci Med 2012; 75(8): 1417-25.

34. Li Y, Marshall CM, Rees HC, Nunez A, Ezeanolue EE, Ehiri JE. Intimate partner violence and HIV infection among women: a systematic review and meta-analysis. J Int AIDS Soc 2014; 17: 18845.

35. Lehrer EL, Lehrer VL, Krauss RC. Religion and intimate partner violence in Chile: macro- and micro-level influences. Soc Sci Res 2009; 8(3): 635-43.

36. Clements C, Ogle R, Sabourin C. Perceived control and emotional status in abusive college student relationships: an exploration of gender differences. J Interpers Violence 2005; 20(9): 1058-77.

37. Sabina C. Individual and national level associations between economic deprivation andpartner violence among college students in 31 national settings. Aggress Behav 2013; 39(4): 247-56.

38. Straus MA, Hamby SL, Boney-McCoy S, Sugarman DB. The revised Conflict Tactics Scales (CTS2) development and preliminary psychometric data. J Family Issues 1996; 17: 283-316.

39. Steptoe A, Wardle J. Cognitive predictors of health behaviour in contrasting regions of Europe. Br J Clin Psychol 1992; 31: 485-502.

40. Sikkema KJ, Watt MH, Meade CS, Ranby KW, Kalichman SC, Skinner D, Pieterse D. Mental health and HIV sexual risk behavior among patrons of alcohol serving venues in Cape Town, South Africa. J Acquir Immune Defic Syndr 2011; 57(3): 230-237.

41. Weir SS, Tate JE, Zhusupov B, Boerma JT. Where the action is: monitoring local trends in sexual behaviour. Sex Transm Infect 2004; 80 Suppl 2: ii63-ii68.

42. Peltzer K, Pengpid S. Dual protection, contraceptive use and HIV risk among a sample of South African male and female students. Gender Behav 2008; 6(2): 1858-1869.

43. World Health Organization (WHO). Guidelines for 


\section{Peltzer \& Pengpid}

controlling and monitoring the tobacco epidemic. Geneva, Switzerland: WHO, 1998.

44. Kimerling R, Ouimette P, Prins A, Nisco P, Lawler C, Cronkite R, Moos RH. Brief report: Utility of a short screening scale for DSM-IV PTSD in primary care. J Gen Intern Med 2006; 21(1): 65-67.

45. Andresen EM, Malmgren JA, Carter WB, Patrick DL. Screening for depression in well older adults: Evaluation of a short form of the CES-D (Center for Epidemiologic Studies Depression Scale). Am J Prev Med 1994; 10(2): 77-84.

46. Wardle J, Steptoe A. The European Health and Behaviour Survey: rationale, methods and initial results from the United Kingdom. Soc Sci Med 1991; 33: $925-$ 36.

47. Koenig HG, Büssing A. The Duke University Religion Index (DUREL): A five-item measure for use in epidemological studies. Religions 2010; 1: 78-85.

48. Lachman ME, Weaver SL. The sense of control as a moderator of social class differences in health and well-being. J Person Soc Psychol 1998; 74(3): 763 773.

49. Brock D, Sarason I, Pierce G. Simultaneous assessment

\section{Intimate Partner Violence}

of perceived global and relationship-specific support. J Social Pers Relationships1996; 13: 143152.

50. World Bank. New Country Classifications, 2014. Available online: data.worldbank.org/news/newcountry-classifications (accessed on 5 October 2015).

51. Weiser SD, Leiter K, Heisler M, McFarland W, Percy-de Korte F, DeMonner SM, Tlou S, Phaladze $\mathrm{N}$, Iacopino V, Bangsberg DR. A population-based study on alcohol and high-risk sexual behaviors in Botswana. PLoS Med 2006; 3(10): e392.

52. Romito P, Grassi M. Does violence affect one gender more than the other? The mental health impact of violence among male and female university students. Soc Sci Med 2007; 65(6): 1222-34.

53. Nasir K, Hyder AA. Violence against pregnant women in developing countries: review of evidence. Eur J Public Health 2003; 13(2): 105-7.

54. Heise L, Ellsberg M, Gottmoeller M. A global overview of gender-based violence. Int $\mathrm{J}$ Gynaecol Obstet 2002; 78 Suppl 1: S5-14.

55. Reed E. Intimate partner violence: a gender-based issue? Am J Public Health 2008; 98(2): 197-8 